\title{
Editorial, v. 6, n. 1, 2012
}

Prezados leitores,

É com satisfação que apresentamos o primeiro número do volume 6 de 2012. Essa edição, composta por treze artigos, trata de temas em evidência na área, entre eles: indicadores de sustentabilidade, responsabilidade social corporativa, comportamento ambiental de consumidores, resíduos de construção e demolição, contabilidade ambiental e eficiência energética.

No primeiro artigo, "Índices de desenvolvimento sustentável para localidades: uma proposta metodológica de construção e análise”, Maria de Fatima Martins e Gesinaldo Ataíde Candido propõem uma metodologia para construção e análise do Índice de Desenvolvimento Sustentável para Municípios (IDSM), a partir da coleta, tratamento e análise de indicadores de sustentabilidade específicos e a classificação dos níveis de sustentabilidade dessas localidades em ideal, aceitável, alerta e crítica.

O segundo artigo, "Evidenciação ambiental de empresas de setores potencialmente poluidores listadas no Índice de Sustentabilidade Empresarial (ISE)", de Araceli Farias de Oliveir, Débora Gomes Machado e Ilse Maria Beuren, identifica o nível de evidenciação de caráter ambiental divulgado voluntariamente pelas empresas potencialmente poluidoras listadas no Índice de Sustentabilidade Empresarial (ISE).

No terceiro artigo, "Conquista e desafios na cadeia produtiva da cajucultura no Rio Grande do Norte: uma análise à luz do desenvolvimento regional sustentável", de Marcos Adller de Almeida Nascimento, Washington José de Souza e Juarez Azevedo de Paiva investigam o ramo da Cajucultura e a interpretação do Comitê Gestor da Cadeia no Rio Grande do Norte das dimensões econômica, social e ambiental da sustentabilidade nesse setor.

No quarto artigo, "Visões de sustentabilidade dos atores da cadeia produtiva dos produtos florestais não-madeiráveis", os autores Osmar Siena, Carlos André da Silva Müller e Dirlei Terezinha Fachinello analisam a concepção de extrativismo e as visões de sustentabilidade e sua relação com as visões ambientalistas dos atores da cadeia produtiva dos produtos do extrativismo florestal não-madeirável no estado de Rondônia (Brasil). Concluíram que o baixo valor agregado dos produtos e a precárias condições de vida têm influenciado os atores da cadeia do PFNM a enunciar perspectivas conservadoras, com pouca preocupação ambiental.

No quinto artigo, "Responsabilidade social corporativa: um estudo multicasos com pequenas empresas do setor sucroalcooleiro da região de Ribeirão Preto - SP", Fabiana de Lima Silva Borges, Lesley Carina do Lago Attadia Galli e Helenita Rodrigues da Silva Tamashiro procuram identificar as ações ligadas à promoção da responsabilidade socioambiental adotadas por três pequenas empresas fornecedoras do setor sucroalcooleiro e participantes do "Programa TEAR", que é fomentado pelo Instituto Ethos,

No sexto artigo, "Impactos socioambientais das indústrias de Cal no distrito de Soledade do Município de Apodi - RN", Luanna Lívia Gurgel e Jorge Luis Filho descrevem o processo produtivo da indústria da cal, bem como aponta os principais impactos relacionados à exploração dos recursos naturais como o calcário e à extração da vegetação nativa como fontes energéticas. Os resultados da pesquisa apontam para a necessidade de adoção de políticas públicas sobre manejo florestal da caatinga; melhoria nas condições de trabalho e práticas ambientais das indústrias do setor.

No sétimo artigo, "Comportamento ecologicamente consciente do consumidor: adaptação da escala ECCB para o contexto brasileiro", Márcia Zampieri Grohmann, Luciana Flores Battistella, Aline Nadalin Velter e Fernanda Casasola validam a aplicabilidade da Escala de Comportamento Ecologicamente Consciente do Consumidor (ECCB), desenvolvida por Roberts (1996), para o contexto nacional e propõem os ajustes necessários. 
No oitavo artigo, "O Programa de manejo diferenciado e reciclagem de resíduos da Prefeitura de Belo Horizonte", Renato de Oliveira Moraes e Priscila Maria Santiago Pereira apresentam a implantação de um programa para a correção das deposições e reciclagem de resíduos da Construção Civil em Belo Horizonte, implantado com o objetivo de corrigir os problemas ambientais urbanos gerados pela deposição indiscriminada e clandestina de resíduos de construção nas vias urbanas. Este artigo trata de um panorama da situação atual do gerenciamento de resíduo de construção civil no município, como funcionam as unidades de recebimento de pequenos volumes e a importância que isto representa numa abordagem mais atual de gerenciamento integrado de resíduos sólidos municipais.

No nono artigo, "Destinação irregular de resíduos de construção e demolição (RCD) e seus impactos na saúde coletiva", João Alexandre Paschoalin Filho e Gustavo Silveira Graudenz abordam o mesmo assunto do artigo anterior, por meio de uma pesquisa exploratória que relata a situação da deposição irregular de resíduos de construção e demolição (RCD) em três municípios brasileiros e apontam os impactos desta ação ilegal na saúde coletiva.

No décimo artigo, "Análise das pesquisas empíricas de contabilidade ambiental publicadas em periódicos nacionais e internacionais no período de 1992 a 2009”, Suliani Rover, Ariovaldo dos Santos e Bruno Meirelles Salotti analisam as características das pesquisas empíricas de contabilidade ambiental publicadas em periódicos de contabilidade e verificaram uma tendência de crescimento em pesquisas publicadas na área, tanto nas revistas acadêmicas nacionais quanto nas internacionais.

No décimo primeiro artigo, "Perfil das pesquisas na área de gestão de custos ambientais e responsabilidade social do Congresso Brasileiro de Custos de 2005 a 2009", Geovanne Dias de Moura, Odir Luiz Fank, João Roberto Sanches e Jorge Ribeiro de Toledo Filho realizaram uma pesquisa descritiva, por meio de uma abordagem bibliométrica, e análise quantitativa sobre custos ambientais no CBC.

No penúltimo artigo, "Proposta para o ensino da controladoria ambiental nos cursos de graduação de Ciências Contábeis nas IESs brasileiras", Sonia Maria da Silva Gomes, Márcio Santos Sampaio, Tânia Cristina Azevedo e Vilma Geni Slomski apresentam uma proposta de ensino da Controladoria Ambiental nos Cursos de Ciências Contábeis, que consiste em um modelo de ensino interdisciplinar sobre as questões socioambientais.

No último artigo, "Gestão da eficiência energética em edificações das instituições públicas de ensino: um estudo aplicado ao sistema de iluminação aa UTFPR sob a ótica técnica e Econômica", Andrea de Souza, Christian Luiz da Silva, Eduardo Leite Kruger e Jorge Carlos Correa Guerra apresentam os resultados de um estudo realizado na Universidade Tecnológica Federal do Paraná, Campus Curitiba, com o objetivo de analisar os atuais padrões de consumo de energia elétrica para iluminação de ambientes em suas instalações. Os autores concluíram que ações de conservação e eficiência contribuem para o melhor aproveitamento dos recursos do Estado.

Desejamos a todos uma ótima leitura!

Maria Tereza Saraiva de Souza

Editora Científica

Revista de Gestão Social e Ambiental - RGSA, São Paulo, v. 6, n. 1, p. 01- 02, jan./abr., 2012. 